Revista do SELL

v. 6 , no. 2

ISSN: $1983-3873$

\title{
A ESCRITA EPISTOLOGRÁFICA DE CLARICE LISPECTOR E A IMPORTÂNCIA DO GÊNERO EPISTOLAR PARA OS ESTUDOS LITERÁRIOS
}

\author{
THE EPISTOLOGRAPHY WRITTEN BY CLARICE LISPECTOR AND THE IMPORTANCE \\ OF THE EPISTOLARY GENRE TO LITERARY STUDIES
}

\author{
Luciana Aparecida Silva \\ Universidade Federal de Uberlândia
}

\begin{abstract}
RESUMO: Clarice Lispector residiu muitos anos no exterior, em diversos países: Suíça, Estados Unidos, Itália e Inglaterra, em razão do casamento com o diplomata brasileiro Maury Gurgel Valente. Por esse motivo, utilizou as missivas como a principal forma de manter contato com amigos e familiares e para tratar dos mais variados assuntos. As correspondências da autora estão publicadas em três livros: Cartas perto do coração (2000) - engloba as cartas trocadas entre a autora e o escritor Fernando Sabino; Correspondências (2002) - cujos interlocutores eram familiares, amigos, intelectuais, artistas e escritores; e Minhas queridas (2007), obra que reúne a vasta correspondência entre as irmãs Tania, Elisa e Clarice Lispector. Nas missivas trocadas entre a autora e seus interlocutores são tratados os mais diversos assuntos: momentos banais do cotidiano, literatura, arte, política, etc. Além disso, podemos notar que Lispector deixa transparecer aspectos que nos auxiliam na tentativa de desvendar a subjetividade da intrigante escritora que desempenhou vários papéis (mãe, mulher, escritora, amiga, irmã, etc) e utilizou várias "máscaras" ao longo da vida, pois acreditava que "Escolher a própria máscara é o primeiro gesto voluntário humano. E solitário".
\end{abstract}

PALAVRAS-CHAVE: Epistolografia. Clarice Lispector. escrita de si.

\begin{abstract}
Clarice Lispector lived many years abroad in several countries - Switzerland, USA, Italy and England - because she was married to the Brazilian diplomat Maury Gurgel Valente. For this reason, she used the letters as the main way of keeping in touch with friends and family and to treat all kinds of subjects. The matches of the author are published in three books: Cartas perto do coração (2000) - includes the letters between the author and the writer Fernando Sabino; Correspondências (2002) - whose partners were family, friends, intellectuals, artists and writers; and Minhas queridas (2007), a work that brings together the vast correspondence between the sisters Tania Elisa and Clarice Lispector. In the letters exchanged between the author and his interlocutors the most diverse subjects are treated: simple moments of daily life, literature, art, politics, etc. Furthermore, we note that Lispector reveals aspects that help us to find out the subjectivity of this intriguing writer who played many different roles (mother, wife, writer, friend, sister, etc.) and used various "masks" lifelong, because "Choose the mask itself is the first human volunteer gesture. And lonely".
\end{abstract}

KEYWORDS: Epistolography. Clarice Lispector. self writing. 


\section{Revista do SELL}

v. 6 , no. 2

ISSN: $1983-3873$

\section{Introdução}

Em virtude do casamento com o diplomata Maury Gurgel Valente, seu colega de turma na Faculdade Nacional de Direito da Universidade do Brasil, Clarice Lispector residiu quinze anos no exterior. De 1944 a 1959 (ano da separação do casal e retorno definitivo da escritora ao Rio de Janeiro) viveu em diversos países da Europa e nos Estados Unidos, "com algumas interrupções, períodos estes que Clarice veio ao Brasil, mas sempre por pouco tempo, aproveitando ou o intervalo entre as mudanças de um lugar para outro, ou as férias". (GOTLIB, 1995, p. 167). Nesse período, utilizou as cartas como principal meio de comunicação com familiares, amigos e conhecidos.

Graças a essa ausência do país, Clarice escreveu um número considerável de missivas, que se configuram um riquíssimo material de estudo de sua vida e obra, publicadas em uma tríade de livros. Cartas perto do coração, publicado em 2000, reúne cinquenta e uma missivas trocadas entre a autora e o escritor Fernando Sabino; Correspondências, de 2002, livro organizado por Teresa Montero, apresenta cento e vinte e nove cartas cujos interlocutores são familiares, amigos, intelectuais, artistas e escritores. Entre eles, encontramos epístolas endereçadas e/ou recebidas de Lúcio Cardoso, Maury Gurgel Valente, Érico Veríssimo, João Cabral de Melo Neto e Rubem Braga, além de doze escritas às irmãs. A obra Minhas queridas é de 2007, fruto de um minucioso trabalho de Teresa Montero que reuniu cento e vinte cartas escritas por Clarice a suas irmãs Tania e Elisa Lispector.

Tais cartas começaram a se tornar públicas no final da década de 1990, quando Tania Kaufmann (sobrenome que Tania Lispector passou a utilizar depois de se casar) doou doze missivas recebidas da irmã à Biblioteca Nacional, com sede na cidade do Rio de Janeiro. Em Minhas Queridas, a pesquisadora conseguiu reunir um grande volume de missivas inéditas da correspondência ativa da escritora que se encontravam nos arquivos particulares das irmãs Lispector, o que resultou em uma obra de inigualável valor não apenas literário e biográfico, mas também histórico-cultural, tendo em vista que Clarice residiu na Europa em plena Segunda Guerra. O objetivo deste trabalho é comprovar a riqueza de possibilidades que tais escritos abarcam, trazendo a escrita epistolográfica para a cena principal dos estudos literários. Além disso, interessa-nos a Clarice Lispector missivista e o podemos depreender das esferas pessoal e profissional a partir do que a escritora compartilhava com seus interlocutores. 


\section{Revista do SELL}

v. 6 , no. 2

ISSN: $1983-3873$

Assim, buscaremos fazer um entrecruzamento entre vida e ficção tendo em mente que as fronteiras entre as duas vertentes são estreitas e, acima de tudo, movediças.

\section{A carta: história e importância literária}

\subsection{A carta ao longo do tempo}

$\mathrm{O}$ ato de escrever cartas está intrinsecamente ligado à necessidade do homem de se comunicar, de se relacionar com outras pessoas e compartilhar experiências, acontecimentos e opiniões. A utilização da linguagem escrita para longas distâncias foi capaz de viabilizar uma forma de comunicação mais abrangente, aproximando pessoas e povos numa troca mútua que possibilitou entender e modificar a realidade da qual faziam parte.

O vocábulo carta advém do latim charta, que por sua vez se originou do grego chártes, assim como a forma epístola veio do latim epistola,ae, cujo significado é: "comunicação devidamente acondicionada e endereçada a uma ou várias pessoas". (CUNHA, 1998).

A origem das cartas advém da antiguidade, mais especificamente ao Egito Antigo. Cícero é considerado o mais importante mestre da arte epistolar do período, tendo escrito 774 cartas cujo valor literário, histórico e linguístico é incomparável. Em suas epístolas são revelados fatos históricos e políticos da Roma antiga que não são encontrados facilmente em outros documentos. Outros importantes epistológrafos foram Horácio, Sêneca, Ovídio e Plínio. Segundo Pessoa (2002), durante esse período a carta figurou como o principal meio de informação utilizado pelos políticos da época.

As cartas escritas pelo apóstolo Paulo entre os anos 50 - 65 d.C., consideradas sagradas pelo Cristianismo, estão reunidas no Novo Testamento e possuem grande importância histórica, pois tinham o propósito de expandir a doutrina cristã e aproximar os dois mundos: o divino e o terreno.

$\mathrm{Na}$ Europa, durante a Idade Média, as missivas eram muito utilizadas para a comunicação entre imperadores e Papas. Nessa época, a língua utilizada em tais correspondências era o latim. 


\section{Revista do SELL}

v. 6 , no. 2

ISSN: $1983-3873$

Durante o Renascimento as cartas eram muito utilizadas pelos pensadores humanistas para difundir as ideias e a filosofia do movimento renascentista.

No século XIX, a troca de correspondências possuía códigos próprios de etiqueta, como os encontrados no livro Código do Bom-Tom ou Regras da civilidade e de bem viver no século XIX, escrito por José Inácio Roquete no ano de 1845. A obra ressalta que caso o missivista não tivesse boa letra, era necessário primeiramente aprender "a escrever, se não perfeitamente, ao menos de um modo inteligível, porque as pessoas a quem escreveis não estão obrigadas a adivinhar ou o que thes quereis dizer, ou a perder o seu tempo a decifrar o que lhes escreveis". (ROQUETTE, 1997, p. 268).

O manual esclarece ainda outros pontos importantes que deveriam ser levados em consideração na escrita de cartas, como o papel apropriado ao destinatário (de acordo com sexo, idade, posição social, etc). Quanto aos cumprimentos, "é uma espécie de comércio de mentiras de ofício, que regularmente a ninguém enganam [...]. A lisonja civil não prejudica a sociedade; [...] mas não a reprimindo é fácil que degenere em vã adulação, a qual é muito prejudicial". (ROQUETTE, 1997, p. 297).

No ano de 1840, na Inglaterra, surgiu o primeiro selo do mundo, em uma época de crescente desenvolvimento comercial e consolidação dos estados nacionais. Nesse contexto, a comunicação escrita estava se expandindo, graças à invenção da imprensa. Até o século XVI, antes da invenção dos selos, quem pagava os custos postais da carta (transporte e entrega) era o destinatário - o que gerava um grande número de devolução de correspondências. Conhecido como "Penny Black", o primeiro selo foi uma invenção de um membro do parlamento inglês, Sir Rowland Hill, para solucionar definitivamente o problema.

Tal invenção revolucionou os serviços postais do mundo todo, inclusive do Brasil, terceiro país a adotar a prática, após Inglaterra e Suíça. Em agosto de 1843 os correios brasileiros lançaram uma linha de selos com o nome de "Olho de Boi", cujos valores eram de 30, 60 e 90 réis. Com relação ao Brasil, não podemos nos esquecer de que a carta do escrivão Pero Vaz de Caminha é a "certidão de batismo" do nosso país, anunciando ao Rei de Portugal a descoberta do novo mundo - sendo, portanto, a primeira forma de ligação postal entre colônia e metrópole. Por meio dela, a corte portuguesa teve acesso à descrição das belezas da nova terra e de seu povo. 


\section{Revista do SELL}

v. 6 , no. 2

ISSN: $1983-3873$

Ou seja, ao longo dos séculos e nas mais variadas línguas e nações, as cartas continuaram desempenhando seu papel primordial, o de ser o principal meio de comunicação das sociedades letradas.

\subsection{Discurso lacunar}

O estudioso não pode, entretanto, ser ingênuo a ponto de acreditar que tudo o que está grafado no papel é a mais pura verdade: o missivista - principalmente o escritor - é também um fabulador, que faz da escrita epistolar um campo fértil para fazer o que mais entende: descortinar os meandros da linguagem, trabalhar a palavra como forma não apenas de expressão de sentimentos, emoções e fatos, mas também como matéria intrínseca do processo de ficcionalização que toda escrita abarca. O missivista transforma-se em personagem diante de seu interlocutor. De acordo com Aniyar de Castro (1983, p. 11):

\footnotetext{
Assim como numa peça teatral a pessoas têm diferentes papéis a representar, da mesma maneira, na sociedade, as pessoas têm que representar diferentes papéis. [...] São os papéis que se vão desempenhando como em várias peças teatrais, diante da sociedade. Estes papéis proporcionam determinados direitos e obrigações.
}

Há ainda outro ponto importante a se deter: toda correspondência possui lacunas que, na grande maioria das vezes, não podem ser preenchidas, pois não há como recuperar todas as idiossincrasias que uma carta contém, levando-se em conta não apenas a ficcionalização, mas também as dissimulações e os vazios propositais que o missivista deixa transparecer em sua escrita. Nesse caso, o dito é tão importante quanto 0 não-dito, pois os silêncios acerca de determinado assunto compõem uma intenção que não pode - nem deve - ser descartada pelo pesquisador. Da mesma forma, as contradições que por vezes são encontradas também se constituem como forma natural do fluxo da escrita, tendo em vista que o autor transfere para as missivas seus conflitos psicológicos, sociais, estéticos e criativos.

O leitor normalmente possui uma ânsia por preencher as lacunas deixadas pela leitura das cartas, numa tentativa desesperada de encontrar a "verdade" por trás do escrito, a totalidade de um período de vida, dos bastidores de uma obra, de um momento 


\section{Revista do SELL}

v. 6 , no. 2

ISSN: $1983-3873$

histórico-cultural, como se tal tarefa fosse possível. É preciso ter em mente que, no caso de cartas de escritores, estamos lidando com profissionais da arte de utilizar a palavra não apenas como forma de se comunicar, de produzir um discurso:

A carta é um discurso fragmentado, um puzzle de discurso. [...] Obra referencial, a correspondência não conta apenas uma vida, mas toda uma época, o que justifica as abordagens sócio-históricas. Enfim, como na autobiografia, a transparência do "eu" é enganosa, a verdade, problemática. (BEM, 1999, p. 113).

Assim, nenhuma correspondência é integral e este é um dos aspectos fascinantes no estudo epistolográfico. "Por natureza, a correspondência é um texto lacunar. Com os hábitos de leitura, as lacunas, as idiossincrasias, os enigmas [...] nos interessam tanto quantos os momentos plenos de significação". (BEM, 1999, p. 114).

Pela própria natureza textual da carta e suas características enquanto gênero, não podemos ler as correspondências como fazemos com um romance, um conto ou uma poesia. Assim como há vários escritores de cartas, também há diversos tipos de leitores, que reagem de forma distinta aos modos de escrita, à maneira de contar um fato ou expressar uma opinião. Como nos textos literários, o bom leitor de cartas sabe que todo detalhe faz diferença e que há várias possibilidades de abordagens e de interpretações acerca do que o missivista pretendeu transmitir ao seu interlocutor.

Dessa maneira, os textos epistolares despertam curiosidade e fascínio justamente por serem textos privados que não podem ser lidos da mesma maneira que fazemos com os textos ficcionais. Para Leonor Arfuch (2010, p. 46) "[...] talvez seja o caráter íntimo da correspondência e sua suposta 'veracidade' - o fato de não terem sido escritas para um romance - apregoada pelos respectivos autores, que conseguem despertar [...] maior interesse".

\subsection{Carta: gênero obsoleto?}

Atualmente a tecnologia está cada vez mais presente na vida de todos, com computadores de última geração que poupam tempo e facilitam a vida cotidiana, juntamente com modernos aparelhos de celular e tablet com os mais variados aplicativos e funções. A internet possibilita uma comunicação totalmente interativa em tempo real, na 


\section{Revista do SELL}

v. 6 , no. 2

ISSN: $1983-3873$

qual signos verbais, imagens e som de altíssima qualidade atuam concomitantemente de forma a tornar a comunicação muito mais ágil e interessante - tudo isso por um baixo custo. A globalização não permite perda de tempo, a avalanche de informações de todas as partes do mundo, a necessidade de estar a par dos acontecimentos gerou uma multidão de pessoas conectadas vinte e quatro horas por dia.

Nessa conjuntura, o próprio sistema de escrita sofreu transformações, adaptandose às transformações advindas das novas tecnologias. Vemos cada vez mais uma nova relação com os usos da linguagem, que desafiam as relações entre oralidade e escrita. Além disso, vemos o surgimento de novos gêneros discursivos, como o e-mail e o chat que, embora não sejam formas absolutamente novas - tendo em vista que temos a assimilação de um gênero para gerar outros - possuem suas peculiaridades.

Nesse contexto de disseminação de inovações tecnológicas, no qual a comunicação é instantânea, independente da distância geográfica, é interessante pensarmos na comunicação via correio. A carta, em seu suporte tradicional - papel, envelope, selo - já se tornou um meio de comunicação obsoleto. As novas gerações não puderam usufruir de todo o ritual que envolvia a troca de correspondências. A escolha do tipo de papel e do envelope, a caligrafia caprichada e a ansiedade da espera pelo carteiro ficaram no passado. São testemunho de uma época na qual a "qualidade e a cor do papel, timbres, monogramas, marcas d'água, [...] carimbos e selos nos levam ao funcionamento das instituições que colocam em trânsito essa forma de comunicação escrita". (MORAES, 2008, p. 8). Todavia, por manterem seu caráter intrínseco de meio de comunicação interpessoal, podemos dizer que as novidades tecnológicas não fizeram com que a epistolografia esteja desaparecendo completamente, "mas meramente efetuando uma transferência de suporte e de visualidade, enquanto mantém sua função de comunicação interpessoal". (GALVÃO, 1998, p. 54).

\section{Epistolografia e escrita de si}

\subsection{Autobiografia: a necessidade de revelar-se ao outro}

O termo autobiografia tem sua origem na Europa, tendo sido utilizado pela primeira vez em 1789, por Friedrich Schlegel, e seu uso amplamente difundido nas línguas europeias a partir do ano de 1800. 


\section{Revista do SELL}

v. 6 , no. 2

ISSN: $1983-3873$

Embora as autobiografias tenham se desenvolvido e se expandido na época moderna, antes da publicação das Confissões de Santo Agostinho já existiam formas de escritas de si no Ocidente. Ou seja, em épocas remotas os indivíduos já possuíam a vontade de deixar registrada sua maneira de pensar o mundo, as pessoas e as situações, numa tentativa de se afirmar enquanto sujeito e deixar registrada sua atitude confessional (ROCHA, 1992, p. 16).

O desejo de construir a própria identidade, de deixar registrado seu lugar no mundo não é, portanto, uma necessidade do homem moderno. "Como lembra Artières, 'para existir, é preciso inscrever-se: inscrever-se nos registros civis, nas fichas médicas, escolares, bancárias'. [...] Os arquivos nos provêem de recordações e lembranças, [...] garantem-nos uma identidade". (MARQUES, 2003, p. 146).

Entretanto, há uma grande variedade de termos utilizados para tentar designar esse tipo de escrita: autobiografia, escrita de si, memórias, diários, cartas, escrita íntima, escrita confessional. Embora cada um dos termos possua suas especificidades, há um traço comum: a necessidade do autor de se mostrar, se revelar no texto, afirmar sua identidade - numa ânsia de revelar-se o mais sinceramente possível (pelo menos em tese) a si próprio e ao outro.

O missivista, desejando traduzir no papel um diálogo fictício, faz da carta uma espécie de espelho de si mesmo, pois ao se mostrar ao outro se aproxima de si próprio. Dessa forma, o exercício de introspecção figura como uma abertura do eu para o outro. Como afirma Santiago (2006. p. 64), "O texto da carta é semelhante ao alter ego do escritor em busca de diálogos consigo e com o outro".

O estruturalismo questionou, por mais de vinte anos, "o método biográfico, e como a proclamação da 'morte do autor' (Barthes) correspondeu a uma libertação do acto crítico relativamente ao anedotário biografista da tradição histórico-literária". (ROCHA, 1992, p. 23). Na relação autor-obra apenas esta importava, pois o importante era exclusivamente a literariedade. Como o texto era o único objeto de estudo dos estruturalistas, o autor era um mero instrumento para a constituição concreta da obra de arte, não despertando interesse algum nos estudos literários.

Com o retorno da importância do autor como agente fundamental da produção artística, o interesse pela relação vida e obra despertou nos estudiosos uma busca pelos textos autobiográficos, com o objetivo de, por meio deles, tentar o delineamento de uma 


\section{Revista do SELL}

v. 6 , no. 2

ISSN: $1983-3873$

"uma imagem mais completa, mais variada, e talvez mais autêntica do sujeito que se procura". (ROCHA, 1992, p. 26).

Como consequência do crescimento dos gêneros autobiográficos em todo 0 mundo desde o final do século $X X$, os estudos e pesquisas sobre as várias modalidades de escritas de si também se tornaram frequentes no meio acadêmico. Entretanto, por mais que se escreva sobre a própria vida, os acontecimentos, sentimentos e sensações, é impossível refazer a totalidade do que foi vivido, pois a vida é complexa demais para se almejar apreendê-la por completo:

Não cumpre a cada um de nós buscar um fio condutor, pois não há, e se houvesse, seria o resumo de vários fios contraditórios da vida cotidiana com seus imprevistos, incertezas, choques, reviravoltas, arrufos, alegrias, [...]. Todas as gamas dos sentimentos humanos ali estão expostas - como nervo e não como cadáver - à visitação pública. (SANTIAGO, 2006, p. 77).

As missivas possuem um caráter específico de escrita de si, diferindo, assim, de outros gêneros autobiográficos. De acordo com Foucault, a maior peculiaridade do gênero é mobilizar emoções não apenas no remetente, mas também no destinatário, uma vez que ambos são levados a uma autorreflexão: "A carta enviada actua, em virtude do próprio gesto da escrita, sobre aquele que a envia. Assim como actua, pela leitura e a releitura, sobre aquele que a recebe". (FOUCAULT, 1992, p. 145).

Clara Rocha, na obra Máscaras de Narciso - Estudos sobre a literatura autobiográfica em Portugal, afirma que a "descontinuidade, o fragmentarismo são sinais distintivos do diário, que imediatamente o diferenciam da narrativa autobiográfica. $\mathrm{O}$ diário obedece a um modelo de narração intercalada". (ROCHA, 1992, p. 26). Entretanto, não é somente no diário que tais traços estão presentes. O mesmo ocorre com a carta, que intercala assuntos diversos, muitas vezes desconectados, e retrata apenas fragmentos da vida cotidiana, por mais que a intenção do autor muitas vezes seja refazer sua vida no papel.

A importância das cartas deve-se também ao fato de serem "um meio de contar a própria vida e de a legar aos outros [...], e que alguns (Ernst Junger, Vergílio Ferreira) consideram a escrita autobiográfica por excelência". (ROCHA, 1992, p. 42). Embora ao longo do tempo os gêneros autobiográficos tenham evoluído e se modificado, assim como 


\section{Revista do SELL}

v. 6 , no. 2

ISSN: $1983-3873$

o percurso histórico dos estudos literários, a escrita de si sempre esteve presente no cenário das artes:

Ao longo da história literária, variam as coordenadas que servem de pano de fundo à produção literária, diferenciam-se as situações de enunciação e de recepção, os múltiplos canais dão novos contornos aos géneros autobiográficos, acumulam-se as experiências de escrita. Evolui a poética da literatura autobiográfica, mas, no fundo, trata-se sempre de procurar o lugar do eu no mundo, de sondar os mistérios do destino e de conhecer melhor a natureza humana. (ROCHA, 1992, p. 44).

\section{2. À margem do cânone}

Em Uma elegia para o cânone, Bloom afirma que há um verdadeiro enfrentamento entre as obras para garantir um lugar no cânone, tendo em vista ser esta esfera controlada por grupos sociais dominantes - ainda que não haja unanimidade nesse ponto de vista:

O cânone, palavra religiosa em suas origens, tornou-se uma escolha entre textos que lutam uns com os outros pela sobrevivência, quer se interprete a escolha como sendo feita por grupos sociais dominantes, instituições de educação, tradições de crítica, ou, como eu faço, por autores que vieram depois e se sentem escolhidos por determinadas figuras ancestrais. (BLOOM, 1995, p. 27-28).

Embora, até os dias atuais, as cartas não se configurem como textos de valor estético dignos de entrarem no seleto grupo das obras essenciais e de leitura obrigatória da literatura ocidental, é fato que os textos canônicos não são estanques e imutáveis, pois o que é considerado cânone para uma época pode não atingir o mesmo status em outra (e vice-versa). Por esse viés, existe a possibilidade de, daqui a alguns anos, as cartas serem lidas e estudadas sob uma perspectiva que as alce a um patamar estéticoliterário improvável para os dias atuais.

Cada época possui suas especificidades e, com a disseminação e valorização das literaturas ditas "menores", as diversas linhas de pesquisa que atualmente encontramos nas universidades, a proliferação de pesquisadores com novas abordagens e concepções sobre o texto literário, além de outros aspectos que se tornam cada vez mais frequentes no contexto atual, o futuro dos estudos e da crítica literária é uma incógnita. Com relação à tecnologia, o fato das cartas não serem mais um meio de 


\section{Revista do SELL}

v. 6 , no. 2

ISSN: $1983-3873$

comunicação utilizado cotidianamente pode torná-las um objeto de estudo ainda mais fascinante e complexo para as futuras gerações.

Assim, até mesmo a noção de valor estético, que sempre norteou a escolha das obras a serem canonizadas, pode sofrer alterações inimagináveis para a sociedade atual. Por outro lado, é interessante pensarmos se no futuro o cânone ainda existirá, tendo em vista que sua ligação com a classe dominante e com o centro do mundo ocidental é fortemente atacada nos dias atuais. De acordo com Bloom (1995, p. 29), "a escolha estética sempre orientou todo aspecto particular da formação de um cânone, mas esse é um argumento difícil de manter nesta época em que a defesa do cânone literário, como o ataque a ele, se tornou tão fortemente politizado".

Perrone-Moisés afirma que, ao se construir uma história literária, é preciso fazer escolhas - consequentemente, há um julgamento de valor - e não há como fugir de tal concepção, uma vez que sempre será preciso escolher obras cujo valor estético se destaque das demais. Para essa escolha, são utilizados critérios que muitas vezes podem ser arbitrários, elitistas e/ou injustos de acordo com o ponto de vista de uma sociedade, época ou cultura. Dessa maneira, tal julgamento está "implícito em todo discurso histórico, e ainda mais quando se trata de história da arte [...]. Todos concordam com que a história deve ser crítica, mas a concordância seria bem menor se se discutissem os valores que presidem à crítica". (PERRONE-MOISÉS, 1991, p. 143).

Segundo a autora, as obras escolhidas como canônicas no passado podem e devem ser estudadas e apreciadas, pois representam um ponto de partida para que a história literária se mantenha viva. Todavia, a autora afirma o quanto é difícil (senão impossível) definir quais critérios de valor devem ser utilizados:

A modernidade pretende julgar sem critérios; os critérios continuam existindo, mesmo se eles se constituem ad hoc. O que caracteriza o julgamento moderno é que não se julga a partir de critérios mas, ao julgar, criam-se critérios. Na leitura como na escritura, o julgamento é uma questão de invenção. (PERRONE-MOISÉS, 1982, p. 13).

A realidade da epistolografia, nos dias atuais, é a de estar não apenas à margem dos estudos privilegiados de literatura - para muitos estudiosos e críticos ainda é motivo de discordâncias o modo como as epístolas devem ser lidas e analisadas. "Pode ser a carta lida e usufruída como obra de literatura, ou constitui apenas um material auxiliar 


\section{Revista do SELL}

v. 6 , no. 2

ISSN: $1983-3873$

para o conhecimento de seu autor, de problemas relacionados com a sua obra, de suas concepções e de seu ambiente social?" (ANGELIDES, 2001, p. 23).

Rocha (1965) acredita que o autor, mesmo escrevendo cartas com a maior naturalidade possível, não consegue se afastar totalmente do mundo literário, tendo em vista que o exercício da escrita sempre perpassará o viés literário. Dessa maneira, "escrever com os olhos na posteridade torna-se quase inevitável. O que as cartas perdem em frescura ganham em perfeição formal e em estilo. E avizinham-se, portanto, da literatura propriamente dita". (ROCHA, 1965, p. 20).

Pensando por esse viés, qual a concepção de literatura na qual a carta não é considerada texto literário? Terry Eagleton, na obra Teoria da Literatura: uma introdução, apresenta a tentativa de se definir o que é literatura como um problema de difícil solução. Apresentando os mais diferentes textos que englobam as literaturas inglesa e francesa, o autor cita a epistolografia como exemplo de texto literário:

A literatura francesa do séc. XVII conta, além de Corneille e Racine, com as máximas de Rochefoucauld, como os discursos fúnebres de Bossuet, com o tratado de poesia de Boileau, com as cartas de Mme. de Sevigné à filha, e com a filosofia de Descartes e Pascal. (EAGLETON, 1997, p. 1).

O fato da história lidar com universais torna complicado lidar com conceitos, visto não terem limites precisos. Assim, querer uma definição exata de tais conceitos muitas vezes faz o rigor da ciência cair no vazio. As concepções sobre o que é literatura, por exemplo, mudam de acordo com a época e, assim como o mundo está em constante transformação, nossos objetos de estudo também mudam constantemente. As cartas, no campo dos estudos literários, embora sejam vistas ainda com preconceito por acadêmicos mais tradicionalistas, conseguiram um espaço na academia que seria inimaginável décadas atrás.

Assim, o estudo da epistolografia constitui um riquíssimo material para uma reflexão sobre outras formas de se escrever a história literária brasileira, além das comumente utilizadas, partindo da ideia de "formação" como um percurso evolutivo, em constante transformação, que engloba estilos, formas e temas e, ainda, como forma de questionar e/ou superar a tradição.

\section{Clarice missivista e a construção da subjetividade: Quem sou eu?}




\section{Revista do SELL}

v. 6 , no. 2

ISSN: $1983-3873$

Ao analisar as cartas da autora, notamos que estão repletas não apenas de fatos corriqueiros do cotidiano; são também crônicas, diários de viagem, lugar de crítica literária, de ficção, etc. Nádia Batella Gotlib (1995) afirma, a esse respeito, que seu dia a dia é retratado, muitas vezes, como em suas obras. A aproximação com a crônica faz com que fatos banais despertem as mais diversas sensações e reflexões:

O tom despreocupado, que caracteriza o gênero da carta e também da crônica, aparece ao longo de todo o texto, mas a relação de parentesco entre esses dois gêneros se dá logo no início da carta, quando o relato do acontecimento próximo, vivido pela narradora, estimula [...] reflexões. (GOTLIB, 1995, p. 189).

Assim, as cartas possibilitam ao leitor conhecer um pouco mais das múltiplas facetas da mais enigmática escritora brasileira. Em suas cartas, Clarice Lispector escreve sobre si, os outros, o mundo; questiona a criação literária e faz reflexões acerca de questões que povoam a mente humana. Como faz em suas obras, a autora "[...] se inventa ao inventar a personagem. Está diante dela como de si mesma. Em sua escritura errante, autodilacerada, repercute, secretamente e em permanência, a pergunta - Eu que narro, quem sou?" (NUNES, 1995, p. 169, grifos do autor).

Souza (2011, p. 36) afirma que "A explicação para o sentido da existência suscita, portanto, novas formas de subjetivação, conforme lição de Michel Foucault, com vistas a construir uma 'hermenêutica do sujeito', referente ao cuidado de si e do outro".

O fato de estar longe do Brasil e, portanto, afastada tanto de seu público quanto dos amigos, familiares e críticos, deixava Clarice-escritora angustiada e insegura em relação à receptividade de seus livros. Phillipe Lejeune esclarece o quanto é complexa a relação autor/leitor:

Um autor não é uma pessoa. É uma pessoa que escreve e publica. Inscrito, a um só tempo, no texto e no extratexto, ele é a linha de contato entre eles. [...] Para o leitor, que não conhece a pessoa real, embora creia em sua existência, o autor se define como a pessoa capaz de produzir aquele discurso e vai imaginá-lo, então, a partir do que ele produz. (LEJEUNE, 2008, p. 23).

Para o público brasileiro, que pouco conhecia a estreante autora que morava no exterior, Clarice era uma mulher envolta em uma aura de mistério. Esse estigma a 


\section{Revista do SELL}

v. 6 , no. 2

ISSN: $1983-3873$

acompanhou por toda a vida, mesmo depois que se separou do marido e retornou ao Brasil, em 1959. Sua fragilidade, bem como seus medos, dúvidas e expectativas traduzem-se na troca de cartas com diversos missivistas. Apesar de ter lutado para se desvencilhar dos rótulos de "hermética", "difícil" e "antissocial", tais características sempre estiveram ligadas à sua personalidade.

Entretanto, é inegável que a construção (proposital ou não) de tal identidade foi fundamental para a perpetuação do fascínio que, até os dias atuais, ronda o nome Clarice Lispector. Em carta endereçada à irmã Tania, a escritora revela o quanto precisa enfrentar os próprios fantasmas e provar, não apenas aos outros, como a si mesma, que consegue administrar seus conflitos internos:

Tania, achei muita graça na importância que você deu à minha ida à montanha-russa - achei graça porque você acertou. Eu estava mesmo desafiando o mundo naquela hora e provando a todos do que sou capaz! $E$ que sou capaz de agüentar minhas emoções, e que sou capaz de tudo! Era isso que eu estava querendo, por modos indiretos, provar [...]. (LISPECTOR, 2007, p. 257-258).

As irmãs Tania e Elisa sempre foram interlocutoras privilegiadas e Clarice sempre fez questão de manter forte o vínculo que as unia, com correspondências frequentes e que demonstram toda a afeição existente entre elas. Por outro lado, Clarice tinha dificuldade em revelar todas as suas angústias e se abrir completamente mesmo para as irmãs. Considerava, inclusive, que sua vida íntima era demasiadamente complexa para ser compreendida, como podemos verificar em carta de 1945:

Quanto a não poder conversar direito pelas cartas, isso é uma fatalidade e tem que ser por toda a vida... É melhor a gente se habituar. Mesmo pessoalmente é difícil conversar, mesmo quando a conversa é entre duas irmãs que se gostam e se entendem. Mil pensamentos atrapalham, como seja o amor mesmo, a desconfiança de que se esteja vagamente mentindo, a vontade de convencer, etc. [...] Meus problemas são os de uma pessoa doente e não podem ser compreendidos por pessoas, graças a Deus, sãs. (LISPECTOR, 2002, p. 75).

No caso da correspondência das irmãs Lispector, não podemos deixar de salientar que não temos propriamente um "diálogo", tendo em vista que apenas uma voz é ouvida - a de Clarice. É por meio dela que tomamos conhecimento do que as irmãs Ihe 


\section{Revista do SELL}

v. 6 , no. 2

ISSN: $1983-3873$

escreviam; é pelo seu olhar que conhecemos um pouco mais dessas irmãs tão queridas, que tiveram papel tão importante na vida e na profissão da irmã caçula.

A ausência não só motiva, pela nostalgia dos contactos humanos perdidos ou interrompidos, um desejo de reafirmação do campo dos afectos, como provoca também um considerável enriquecimento daquilo que se tem para dizer: outros mundos, geográficos ou espirituais, nutrem de revelações e experiências inéditas o recheio da escrita. (ROCHA, 1965, p. 14-15).

Mais que relações de afeto comuns entre irmãs, as missivas revelam o quanto Clarice considerava importante a opinião de ambas também em relação às suas obras. Em carta escrita em março de 1945, a autora explica à irmã Elisa a dificuldade em fazer alterações no livro O lustre:

Você e Tania sugerem que eu releia e desentorte o livro. [...] É impossível de certo modo tocá-lo, tanto o que nele tem de ruim está misturado à sua essência e ao seu decorrer. Tania me prometeu me dar uma relação de observações a respeito; isso me facilitará porque acordará minha atenção num momento em que meu interesse não pode acordá-la. Nas provas do livro, que pretendo me sejam enviadas, certamente poderei enxergar melhor e modificarei qualquer coisa. (LISPECTOR, 2007, p. 79).

Em outra missiva, dessa vez endereçada ao escritor e amigo Lúcio Cardoso, a autora relata sua decepção ao ser comparada a James Joyce e Virgínia Woolf, em mais uma tentativa de desvincular sua literatura dos referidos escritores:

Lúcio, [...] depois que li o artigo de Álvaro Lins, muito surpreendida, pois esperava coisas porque esperava que ele dissesse coisas piores, escrevi uma carta para ele, afinal uma carta boba, dizendo que eu não tinha "adotado" Joyce ou Virgínia Woolf, que na verdade lera a ambos depois de estar com o livro pronto. [...] Mas a verdade é que senti vontade de escrever a carta por causa da impressão de insatisfação que tenho depois de ler certas críticas, não é insatisfação por elogios mas é um certo desgosto e desencanto - catalogado e arquivado. (LISPECTOR, 2002, p. 43-44).

Segundo a crítica biográfica, é imprescindível compreender que a busca pelo que realmente aconteceu - pelos fatos "verídicos" - não é o mais relevante. Nessa perspectiva, é muito mais interessante pensar na "sua construção narrativa, os modos de (se) nomear no relato, o vaivém da vivência ou da lembrança, o ponto do olhar, o que se 


\section{Revista do SELL}

v. 6 , no. 2

ISSN: $1983-3873$

deixa na sombra; em última instância, que história [...] alguém conta de si mesmo ou de outro eu". (ARFUCH, 2010, p. 73, grifos da autora). Evidentemente sua genialidade, nos dias atuais, é inquestionável e ninguém mais a vê como "plagiária" de tais mestres da literatura universal.

Datada de 1946, a correspondência dirigida ao também amigo Fernando Sabino revela uma Clarice insegura em relação a outra crítica de Álvaro Lins, na qual afirma ter pensado até mesmo em abandonar a literatura:

Encontrei cartas de casa e vários recortes de jornal, [...] E nota de Álvaro Lins dizendo que meus dois romances são mutilados e incompletos, [...] que os personagens não têm realidade, [...] Tudo o que ele diz é verdade. Não se pode fazer arte só porque se tem um temperamento infeliz e doidinho. Um desânimo profundo. Pensei que só não deixava de escrever porque trabalhar é a minha verdadeira moralidade. (LISPECTOR, 2011, p. 22).

Fica evidente a insegurança e a fragilidade da autora frente à crítica e à recepção de seus livros. Ao concordar com o crítico, Clarice revela uma das facetas de sua personalidade: a mulher extremamente insegura quanto ao seu lugar não apenas no ambiente literário, mas no mundo - uma vez que as angústias existenciais são tão brilhantemente trabalhadas em suas obras.

Em uma das cartas endereçadas às irmãs, Clarice assume completamente a "máscara" de esposa, declarando estar se dedicando exclusivamente às obrigações de mulher de diplomata: "Todo esse mês de viagem nada tenho feito, nem lido, nem nada sou inteiramente Clarice Gurgel Valente". (LISPECTOR, 2002, p. 50).

Outra missiva, dessa vez enviada de Nápoles a Lúcio Cardoso, revela o quanto a autora considera tal rotina desgastante não só para ela, mas também para o marido. Embora tenha sempre desempenhado bem esse papel, as regras, cerimônias, superficialidades e formalidades do mundo diplomático a exauriam. Da mesma forma, fica evidente sua impaciência ao lidar com aspectos da natureza humana menos "nobres" e sua vontade de enxergar além das máscaras sociais:

De um modo geral eu tenho feito "sucesso social". Só que depois deles eu e Maury ficamos pálidos, exaustos, olhando um para o outro, detestando as populações e com programas de ódio e pureza. Deus meu, se a gente não se guarda como nos roubam. Todo o mundo é inteligente, é bonito, é educado, dá esmolas e lê livros; mas por que não vão para um inferno qualquer? [...] Quero que todos sejam felizes e me deixem em paz. [...] 


\section{Revista do SELL}

v. 6 , no. 2

ISSN: $1983-3873$

Nunca ouvi tanta bobagem séria e irremediável como nesse mês de viagem. Gente cheia de certezas e de julgamentos, de vida vazia e entupida de prazeres sociais e delicadezas. É evidente que é preciso conhecer a verdadeira pessoa por trás disso. Mas por mais protetora dos animais que eu seja, a tarefa é difícil. (LISPECTOR, 2002, p. 51-55).

A vontade de regressar ao Brasil era imensa; a solidão e a angústia eram constantes, bem como a dificuldade de lidar com a saudade. Morar em um lugar como a Suíça, completamente diferente em vários aspectos - clima, cultura, culinária, hábitos, etc - complicava ainda mais seu estado de espírito, aumentando a falta que sentia de estar ao lado da família, dos amigos, enfim, de morar em seu país:

Em agosto faremos 5 anos de exterior. Não são cinco dias. Cinco anos de não saber o que fazer, cinco anos durante os quais, dia a dia, me perguntei como perguntava a vocês: que é que eu faço? Para vocês terem uma idéia do que tem sido minha vida durante esses anos: para mim todos os dias são domingo. [...] A vida começa a parar por dentro, e não se tem mais força de trabalhar ou ler. [...] Berna é um túmulo, mesmo para os suíços. [...] Acho que a culpa é da excessiva solidão, e dessa longa tarde de domingo que dura anos. (LISPECTOR, 2007, p. 210-211).

Para uma pessoa considerada estrangeira em sua própria terra, que sempre lutou para reafirmar sua identidade de brasileira (tendo diversas vezes lidado com 0 estigma de ter nascido na Ucrânia), as constantes mudanças só agravavam sua sensação de não pertencimento a nenhum lugar, como verificamos em carta enviada de Torquay às irmãs, no ano de 1950:

Vocês não podem imaginar como estamos cansados de viagens e mudanças. Estamos espiritualmente cansados, fisicamente cansados. [...] O corpo e a cabeça ficam constantemente procurando uma adaptação, a gente fica fora de foco, sem saber mais o que é e o que não é. Nem meu anjo da guarda sabe mais onde moro. (LISPECTOR, 2007, p. 234).

Embora o ato de escrever fosse essencial para Clarice Lispector, o papel de mãe a realizava como ser humano, como declarou (apud Gotlib, 2005, p. 287): "Eu não queria que meus filhos sentissem a mãe-escritora, mulher ocupada, sem tempo pra eles. [...] Eu sentava num sofá, com a máquina de escrever nas pernas e escrevia. Eles, pequenos, podiam me interromper a qualquer momento. E como interrompiam". A maternidade, como outros campos de sua vida, não foi uma experiência fácil. Seu filho mais velho, Pedro, sofria de esquizofrenia e, apesar de evitar tocar no assunto com amigos, a 


\section{Revista do SELL}

v. 6 , no. 2

ISSN: $1983-3873$

impotência diante da doença do filho a dilacerava. Após se separar do marido, criou os filhos sozinha, passando por dificuldades financeiras e emocionais, mas sempre teve orgulho de ser mãe. Seu amor incondicional é evidente em suas cartas, como a endereçada ao filho caçula, Paulo, quando este embarcou para os Estados Unidos no ano de 1969, a fim de fazer intercâmbio:

Há pouco tempo, Gafanhoto, você subia pelas minhas pernas para ficar no meu colo. É com orgulho ver você alto, fisicamente feito, e independente sobretudo. Hoje, dia seguinte da sua partida, ocupei-me o tempo todo para disfarçar a saudade. [...] Hoje felizmente Pedro foi ao cinema com tia Elisa. Imagine você que ele tinha inventado tantas coisas más a respeito de cinema que não queria mais ir. Mas, se Deus quiser, de agora em diante ele perderá o medo. (LISPECTOR, 2002, p. 262-262).

$O$ ato de escrever cartas, por conseguinte, tem papel fundamental na construção identitária do indivíduo, no qual o dito é tão importante quanto o não-dito, e a preservação/exposição da vida e da intimidade passam pelo crivo altamente seletivo dos missivistas. Ao optar por expor ou omitir fatos, opiniões e sentimentos de acordo com suas intenções no momento da escrita, o sujeito passa a construir uma personagem de si mesmo a partir dos espaços que ocupa, das ligações afetivas, profissionais e familiares, da sua maneira de se conectar com a própria individualidade e com o outro.

Assim, "o eu - a consciência de si - que se enuncia a partir de uma absoluta particularidade busca já, ao fazê-lo, a réplica e a identificação com os outros, aqueles com os quais compartilha o habitus social". (ARFUCH, 2010, p. 49, grifos da autora).

Destarte, Clarice assume diversos papéis: é mulher, mãe, amiga, escritora, personagem, máscara de si mesma. Transforma seus escritos em lugares nos quais tenta se encontrar como ser humano, lidar com conflitos internos e buscar outras formas de compreender seu intenso e indomável mundo interior. O papel de seus interlocutores foi extremamente importante em sua vida, pois o diálogo com pessoas cujo vínculo afetivo era forte a auxiliaram a encontrar-se como pessoa, superar medos e buscar sentido em sua existência.

Em cada palavra dita ou omitida, os significados nunca são estanques, pelo contrário, estão em constante mutação, ainda mais se levarmos em consideração que uma das idiossincrasias da autora sempre foi a utilização da escrita como forma de adentrar os obscuros labirintos da mente humana. 


\section{Revista do SELL}

v. 6 , no. 2

ISSN: $1983-3873$

No caso de Clarice Lispector, as missivas tornam-se, consequentemente, um jogo de espelhos no qual a reflexão crítica sobre os atos de ler-escrever-viver adquire papel fundamental tanto na construção e amadurecimento do processo criativo quanto em sua constituição como sujeito e de seu respectivo papel no mundo.

\section{Considerações finais}

O intuito deste trabalho foi o de colocar a carta em papel de destaque, como protagonista e não como mera coadjuvante nos estudos literários, apontando para a vasta riqueza escondida no gênero - que merece ser amplamente explorada.

Após nossa análise, verificamos que as missivas de Clarice Lispector revelam uma pessoa atormentada pela literatura em si e pelo aprimoramento e reconhecimento de seu processo criativo. Mais que isso, descortinam as múltiplas facetas identitárias de uma mulher que lutou contra preconceitos (ter nascido na Ucrânia e ter se separado do marido quando o assunto era verdadeiro tabu na sociedade), e cuja personalidade era, ao mesmo tempo, frágil e desafiadora. $O$ fato de ter transformado sua vida em palco de experimentações estéticas fez de seus interlocutores personagens fundamentais na sua busca por encontrar-se como ser humano e como profissional.

Clarice, na famosa entrevista a Júlio Lerner (apud GOTLIB, 2005, p. 458), afirma: "Eu escrevo sem esperança que o que eu escrevo altere qualquer coisa. Não altera em nada". Ela sempre teve consciência de que o papel do escritor não é o de viver em um mundo imaginário, utópico. Entretanto, escrever para "transformar o mundo" é muitas vezes arriscado, pois a frustração é quase certa. Mesmo assim, sempre teve consciência de que era imprescindível escrever como forma de continuar viva, de se encontrar como pessoa, de entender seu "eu" volúvel, em constante transformação e integração com o "outro".

Podemos notar a utilização das missivas como forma de, a partir do olhar do outro, perscrutar a si mesma. Dessa maneira, seu intento foi tornar possível a construção de sua subjetividade a partir dos traços, lacunas e borrões que os intercâmbios epistolares ajudam a entender, construir, preencher e desconstruir. A utilização de máscaras revela sua tentativa de esconder suas fragilidades, inseguranças e fraquezas, ou seja, para se proteger do mundo e, por que não dizer, de si própria. 


\section{Revista do SELL}

v. 6 , no. 2

ISSN: $1983-3873$

Concluímos, como havíamos proposto, que a autora fazia de seus correspondentes não apenas confidentes, como importantes personagens de sua produção literária. Nas cartas podemos notar sua angústia com o ato da escrita e a recepção de seus livros, bem como sua inadequação à formalidade e superficialidade do mundo diplomático, tão distante de sua natureza "selvagem".

A possibilidade de re(inventar) a própria vida e de encontrar seu lugar como mulher e escritora abre espaço para o estudo de sua epistolografia não apenas como meio de aprofundar e lançar luz aos bastidores do processo de criação literária, mas também possibilita desvendar as múltiplas identidades de uma mulher que fez da ficção a mola propulsora de sua existência.

\section{Referências:}

ANGELIDES, Sophia. Carta e Literatura: correspondência entre Tchekhov e Gorki. São Paulo: Editora da Universidade de São Paulo, 2001.

ANIYAR DE CASTRO, Lola. Criminologia da reação social. Trad. Ester Kosovski. Rio de Janeiro: Forense, 1983.

ARFUCH, Leonor. O espaço biográfico: dilemas da subjetividade contemporânea. Trad. Paloma Vidal. Rio de Janeiro: EdUERJ, 2010.

BEM, Jeanne. O estatuto literário da carta (Le statut littéraire de la lettre). Trad. Cláudio Hiro. Génesis: Révue Internationale de Critique Génétique, № 13, Paris, 1999, p. 113115.

BLOOM, Harold.Uma elegia para o cânone. In: O cânone ocidental. Rio de Janeiro: Objetiva, 1995. p. 23-47.

CUNHA, Antônio Geraldo da. Dicionário Etimológico Nova Fronteira da Língua Portuguesa. 3.ed. Rio de Janeiro: Nova Fronteira, 1998.

EGLETON, Terry. Teoria da Literatura: uma introdução. São Paulo: Martins Fontes, 1997.

FOUCAULT, Michel. O que é um autor. Lisboa: Passagens/Veja Editora, 1992.

GALVÃO, Walnice Nogueira. Desconversa (Ensaios críticos). Rio de Janeiro: Editora da UFRJ, 1998.

GOTLIB; Nádia Battella, Clarice Lispector: uma vida que se conta. São Paulo: Ática, 1995. 


\section{Revista do SELL}

v. 6 , no. 2

ISSN: $1983-3873$

LISPECTOR, Clarice. Minhas Queridas. Rio de Janeiro: Rocco, 2007.

Correspondências. Rio de Janeiro: Rocco, 2002.

LEJEUNE, Phillipe. O pacto autobiográfico: de Rousseau à internet. Trad. Jovita Gerheim Noronha, Maria Inês Coimbra Guedes. Belo Horizonte: UFMG, 2008.

MARQUES, Reinaldo. O arquivamento do escritor. In: SOUZA, Eneida Maria de; MIRANDA, Wander Mello. Arquivos literários. São Paulo: Ateliê Editorial, 2003. p. 141156.

MORAES, Marcos Antonio de. Sobrescrito. In: Teresa Revista de Literatura Brasileira / área de Literatura Brasileira. Departamento de Letras Clássicas e Vernáculas Faculdade de Filosofia, Letras e Ciências Humanas. Universidade de São Paulo - oㅜ /9. São Paulo: Ed. 34, 2008, p. 8 e 9.

NUNES, Benedito. O drama da linguagem: uma leitura de Clarice Lispector. São Paulo: Ática, 1989.

PERRONE-MOISÉS, Leyla. Escolher e/ é julgar. In: Colóquio Letras, Lisboa, n. 65. p. 513, jan. 1982.

PESSOA, Marlos de Barros. Da Carta a Outros Gêneros Textuais. In: Maria Eugênia Lamoglia Duarte e Dinah Callou (orgs.) Para a história do português brasileiro. Vol. IV. Notícias de corpora e outros estudos Rio de Janeiro: UFRJ/ FAPERJ, 2002.

ROCHA, Andrée Crabbé. A epistolografia em Portugal. Coimbra: Editora Almedina, 1965.

ROCHA, Clara. Máscaras de Narciso: Estudos sobre a literatura autobiográfica em Portugal. Coimbra: Editora Almedina, 1992.

ROQUETTE, José Inácio. Código do Bom-Tom ou Regras da civilidade e de bem viver no século XIX. Org. Lilia Moritz Schwarcz. São Paulo: Companhia das Letras, 1997, p. 266-300.

SABINO, Fernando; LISPECTOR, Clarice. Cartas perto do coração. 8 ed. Rio de Janeiro: Record, 2011.

SANTIAGO, Silviano. Suas cartas, nossas cartas. In: . Ora (direis) puxar conversa! Ensaios Literários. Belo Horizonte: Editora UFMG, 2006. 